\title{
Petroleum Reserves and the Credibility Gap
}

\author{
Hassan S. Naji \\ Faculty of Earth Sciences, \\ King Abdulaziz University, Jeddah, Saudi Arabia \\ hassan@petrobjects.com
}

\section{Received: 5/2/2006}

Accepted: 1/10/2006

\begin{abstract}
This paper focuses on studying the available definitions of petroleum reserves and the resulting credibility gap. The credibility gap refers to the apparent disparity amongst the reported petroleum reserves values. There are two main reasons for this gap; the first reason is that there is no consistent definition of petroleum reserves. In fact there are many definitions available today in the oil industry. In addition, the wording of each definition is sufficiently vague allowing evaluators a great deal of latitude when classifying reserves. Furthermore, oil companies tend to use definitions that fulfill their specific goals. This misuse, along with the companies' pressure to look good in the financial market, has led to a bending of the rules. Consequently, it is necessary to adopt a consistent definition with clear wording in order to enhance communication and to avoid a situation where the definition of petroleum reserves loses all meanings.
\end{abstract}

The second reason for the gap is that petroleum reserves are not measurable quantities; they are only estimates. As a matter of fact there is no single estimation method and there is always uncertainty in each method. This reason coupled with the countries' underlying politics and prevailing economics govern the credibility of the reported reserves values. Therefore, it is necessary to provide a methodology for estimating reserves on a common basis in order to improve the support for financial reporting and to attract the public financing.

Keywords: Petroleum Reserves; Reserves Definitions; Reserves Values. 


\section{Introduction}

Petroleum is the major factor in the continued development of the world's countries. Therefore, it is essential for the countries future planning to have a clear assessment of their petroleum reserves. Petroleum reserves values reported in the oil industry periodicals may not be realistic and may not reflect the actual reserves values. The countries' underlying politics and prevailing economics govern the credibility of the reported reserves values. In addition, there are many definitions for the petroleum reserves available today, each one fulfilling a specific purpose. Furthermore, the wording of each definition is sufficiently vague, allowing evaluators a great deal of latitude when classifying reserves. Many companies and agencies retain their own definitions. Such definitions, while close to the SPE standard, have certain idiosyncrasies, which result from law and regulatory requirements, corporate policy decisions and/or ingrained habit. This freedom, coupled with companies' pressure to look good in the financial market, has resulted in a bending of the rules.

Until two decades ago, reserves estimation was not a big issue, because reservoirs were much more conventional and less risky. Natural gas was not a valuable commodity and, in fact, there was an oversupply. Oil reserves were also greater than demand, resulting in a pro-rationing system; which kept everyone honest, since everyone was scrutinizing everyone else's reserve estimates (Laherrere, 1998). In today's environment, however, everything is for sale, from reserves to processing plants to companies. There is a great need for raising capital on the public market as there is a good demand for both oil and natural gas. With conventional sources becoming depleted, the oil industry is directing itself towards higher risk ventures, such as shallow gas, heavy oil, and the more complex reservoirs.

Because of this seeming lack of control and in order to avoid a situation where reserves lose all meanings as a comparative measure, many associations today are attempting to standardize reserve definitions and set up enforcement organizations. Without a definition as a guideline or reference, a volume labeled as reserves could be anything but would have no meaning to anyone (Robinson, 2000). It comes as no surprise, then, that there must be a means of harmonizing those definitions and tighter controls need to be put in place when making reserves estimates. This is necessary for the following reasons:

1. Enhance communication;

2. Make terms comparable and compatible;

3. Provide a methodology for evaluating resources on a common basis;

4. Improved support for financial reporting; and

5. Attract public financing. 


\section{Relevant Terms}

\section{Petroleum}

Petroleum refers to the naturally occurring liquids and gases which are predominantly comprised of hydrocarbon compounds. It may also contain nonhydrocarbon compounds; such as nitrogen, carbon dioxide, and hydrogen sulfide.

\section{Crude Oil}

Crude oil is a mixture of hydrocarbons that exists in a liquid phase in natural underground reservoirs and remains liquid at atmospheric pressure after passing through surface separating facilities. Production volumes reported as crude oil include: Liquids technically defined as crude oil; small amounts of hydrocarbons that exist in the gaseous phase in natural underground reservoirs, but which are liquid at atmospheric pressure after being recovered from the oil well (casing head), and gas in lease separators; small amounts of non-hydrocarbons produced with the oil.

\section{Natural Gas}

Natural gas is a mixture of hydrocarbon compounds and small quantities of various non-hydrocarbons existing in the gaseous phase or in solution with oil in natural underground reservoirs at reservoir conditions.

\section{Natural Gas Liquids (NGLs)}

Natural gas liquids (NGLs) are those reservoir gases liquefied at the surface in lease separators, field facilities or gas processing plants. NGLs consist of field condensates and natural gas plant products such as ethane, pentane, propane, butane and natural gasoline.

\section{Recovery Factor}

Recovery factor depends on the geology and quality of the reservoir. For example, for tight reservoirs, the recovery factor is low, within the range $3-10 \%$, and for porous and permeable reservoirs, it is high, may go up to $80 \%$. Similarly, the recovery method adopted, whether primary or secondary, and the quality of production scheme will assuredly have a strong influence on the recovery factor. Not to mention the effect of technology adopted in depleting the reservoir.

\section{Reserve Growth}

Reserve growth is defined as the increase in the successive estimates of reserves. It has been observed in almost all fields or provinces, but most notably 
in mature petroleum provinces. It is the most important problem in assessing the future production. Statistically reserves growth occurs because reserves are badly estimated.

\section{Reported Reserves Values}

The sources that report values of the world oil and gas reserves are grouped into two main sources: the oil industry periodicals, and the independent agencies. The oil industry periodicals are: the Oil \& Gas Journal (OGJ), the British Petroleum Amoco (BP), the World Oil, and the OPEC Annual Statistical Bulletin (ASB). The most common independent agencies are the United States Geological Survey (USGS) and Petroconsultants. Those agencies provide independent estimates after they have recognized the inconsistent nature of the reserves values reported in the trade journals and periodicals (Haider, 2000).

The data reported in the OGJ comes from a questionnaire distributed to the different countries and is reported as received. When a country fails to reply to the questionnaire, the numbers are carried forward to the following year. However, if the country makes an official declaration reporting new reserves, the numbers are adjusted in the following issues of the journal (Haider, 2000, and Psenner, 2004).

BP simply reproduces the numbers reported by the OGJ, with the following slight adjustments (Haider, 2000): 1) Numbers are shown to represent end-ofyear (December 31) rather than beginning of the following year (January 1). 2) Estimates of the NGL reserves are added to the USA and Canada oil reserve figures. There is no proof, however, that estimates of all other countries include their NGL figures as well. 3) Higher numbers are reported for Azerbaijan and Kazakhstan in recent years without specifying the source or reasons for the differences.

The BP numbers are the most widely quoted and used by experts and nonexperts alike. The analysts who use these numbers assume that they must have the support of the renowned oil company. In addition to the confusion when a note next to the number says "proved reserves" conveying some sort of technicality to the term (Laherrere, 1998). World Oil poses similar questionnaire to the countries, yet some reported numbers are significantly different than those of OGJ and BP, especially for OPEC countries (Haider, 2000).

The numbers reported in the OPEC ASB are based on direct communications to the Secretariat, as well as various other sources, such as the Middle East Economic Survey, Petroleum Intelligence Weekly, Arab Oil and Gas, and, of course after verification and comparisons, the OGJ, BP, and World Oil (Psen- 
ner, 2004). OPEC numbers are taken to represent accurate figures, since OPEC is a professional international organization, and their numbers are produced in an impressive volume with other energy data. Most of the OPEC member countries are reporting their data on reserves based on the Society of Petroleum Engineers (SPE)/World Petroleum Congress (WPC) definitions (Al-Tayyeb and Dehmani, 2003). Still, however, the reported values may not reflect the actual reserves values. For example, if we take a look at the proven crude oil reserves for the total OPEC and several member countries during the years 1962 to 2003 as shown in Fig. 1-7, we see that there is a sudden jump in the proven reserves between the years 1982 to 1988 .

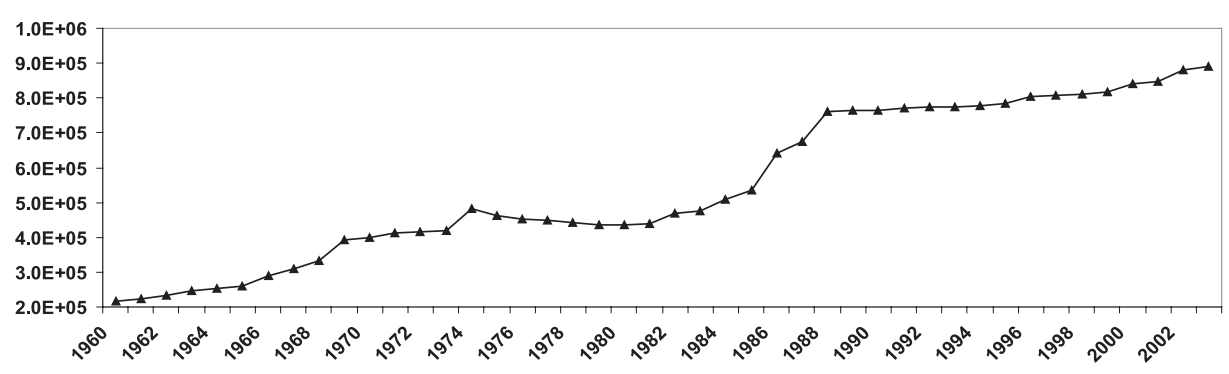

Fig. 1. Total OPEC proven crude oil reserves, million barrels.

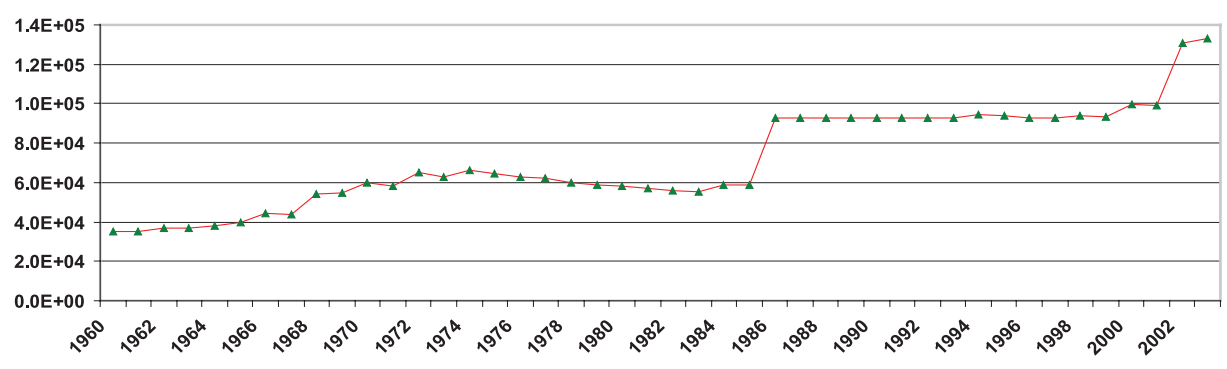

Fig. 2. Iran proven crude oil reserves, million barrels.

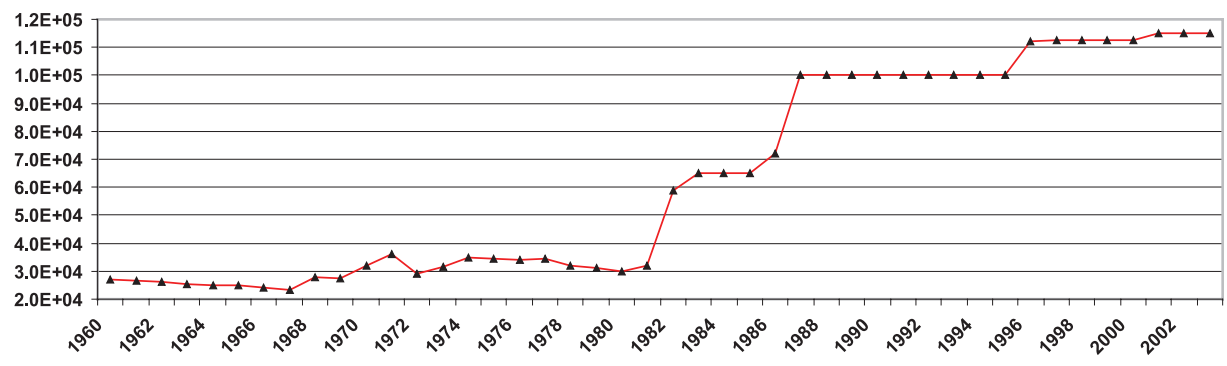

Fig. 3. Iraq proven crude oil reserves, million barrels. 
54

H.S. Naji

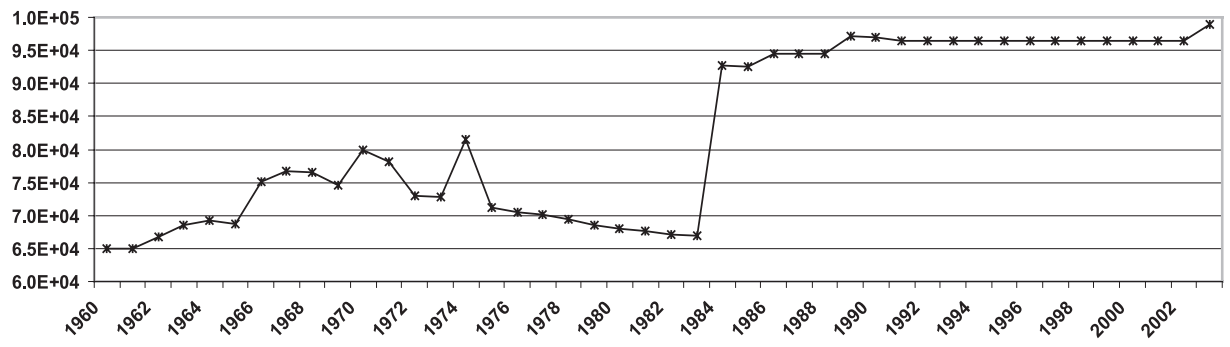

Fig. 4. Kuwait proven crude oil reserves, million barrels.

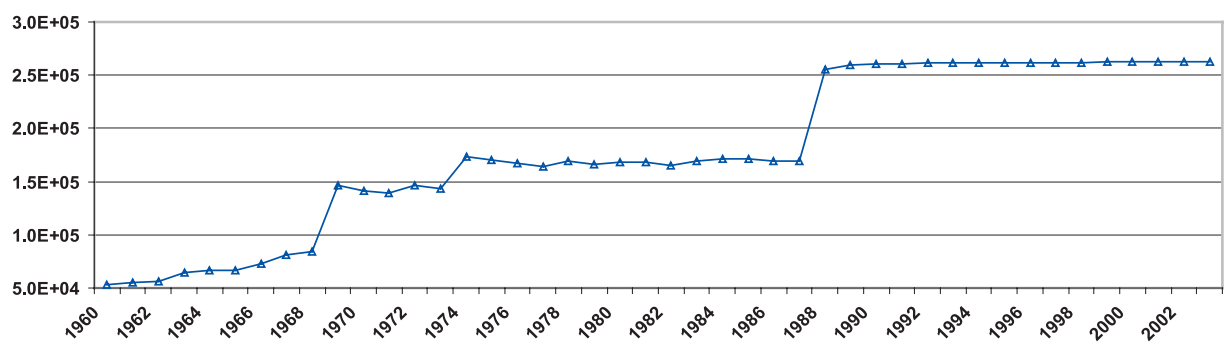

Fig. 5. KSA proven crude oil reserves, million barrels.

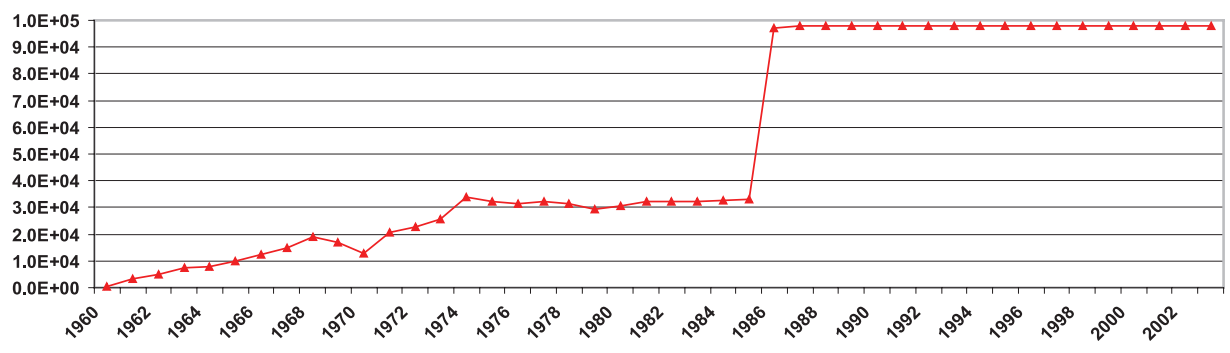

Fig. 6. UAE proven crude oil reserves, million barrels.

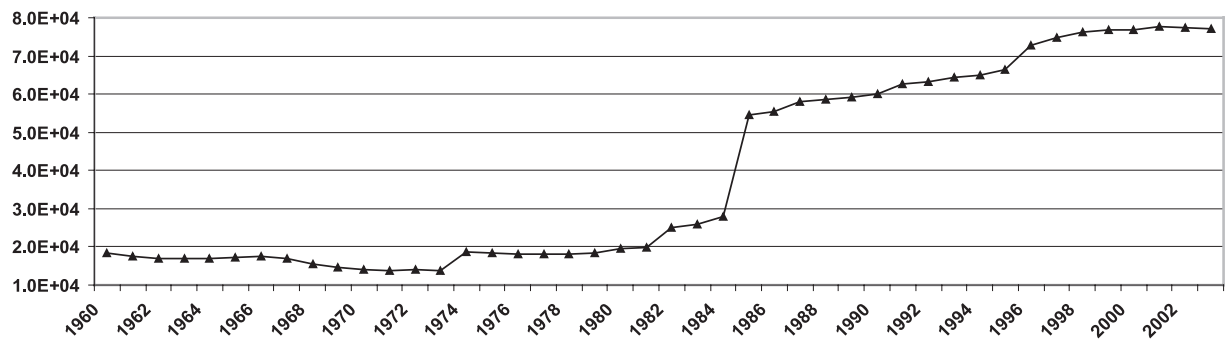

Fig. 7. Venezuela proven crude oil reserves, million barrels. 
As stated by Salameh, 2004, the reason for this jump is that each OPEC member country was assigned its quota based on its annual production capacity. However, in the early 1980, the organization changed the rule to also consider oil reserves. As a result, several OPEC member countries increased their reserves estimates in order to secure for themselves a bigger production share.

It comes as no surprise, then, that tighter controls need to be put in place. In addition, there must be a common procedure when making reserves estimates.

\section{Historical Development of Reserves Definitions}

The American Petroleum Institute (API) was the first agency that set the definition of reserves in the mid-1930's. From 1936 to 1964, the American Petroleum Institute (API) set the standards for definitions of Proved Reserves. This effort was joined by the American Gas Association (AGA) in 1946 with the joint API-AGA annual publication of "Proved Reserves of Crude Oil, Natural Gas Liquids and Natural Gas." In 1964, the Society of Petroleum Engineers (SPE) issued reserve definitions, which agreed closely with the revised API definitions."

The events of the 1970's and the resulting changes in the oil industry led to the issuance of definitions by the Security and Exchange Commissions (SEC) in 1979, by SPE in 1981 and by the World Petroleum Congress (WPC) in 1983. SPE revised its definitions in 1987 and, in cooperation with WPC, again in 1997. Until 1983 all reserves definitions, at least those issued by recognized authorities such as API and SPE, were for Proved Reserves only. The WPC definitions of 1983 included categories ranging from Proved to "Speculative" Reserves. The 1987 SPE definitions were the first to formally define Proved, Probable and Possible. This does not mean that the terms were not in use or that Probable and Possible reserves had not been calculated and reported. Producing companies, consulting firms, banks and government agencies developed their own criteria for Unproved Reserves and used them (Occidental, 2002).

Despite the efforts of SPE, WPC, and SEC to standardize reserves, multiple reserves definitions remain in use. Many companies and agencies retain their own definitions which, while close to the SPE standard, have certain idiosyncrasies resulting from law and regulatory requirements, corporate policy decisions and/or ingrained habit. This is particularly true regarding the boundary between Proved and Unproved and, to a lesser extent, the sub-categories within Proved. The following reserves definitions are available today in the oil industry:

1. ARPS 1962 reserves classification

2. The SPE/API 1965 reserves definitions

3. The McKelvey Box resource classification system

4. The SEC definition of 1979 
5. The 1981 SPE definitions

6. The 1988 SPE definition

7. The SPE/WPC definitions

8. The SPE/WPC/AAPG definitions

9. The UNFC classification system

10. The SPEE expansions of the SPE 1987 and 1997 definitions

11. The California State Board of Equalization (SBOE) definition contained in rule 468 of the California R\&T Code.

12. Canadian reserves definitions

13. Chinese classification system

14. The CCOP classification system

The SPE and SPE/WPC definitions are intended to provide industry and observers of the industry, consultants and the financial (lending) community with a standard to which all evaluators should conform. The 1981 and 1987 SPE definitions succeeded in providing that standard for domestic use, and the 1997 SPE/WPC collaboration attempted to provide an international standard. In any case, SPE is considered to be the industry standard.

The SEC definitions are the response of government to the perceived need for a benchmark by which producing companies could be compared to each other. The primary beneficiary of this effort is the equity financial community and consulting firms. The SPEE expansion of the SPE definitions is included because of the extensive explanation of the SPE definitions rendered by SPEE and the historical context for these definitions provided by SPEE.

The first version of the United Nations Framework Classification (UNFC) for Energy and Mineral Resources was initiated in 1992, for Solid Fuels and Mineral Commodities, on the basis of a proposal made by the German Government. In November 2001, an Intergovernmental Ad Hoc Group of Experts was created. The main purpose of the Ad Hoc Group of Experts was to extend the principles of the UNFC for Solid Fuels and Mineral Commodities to other energy resources (oil, natural gas and uranium) covering the specific aspects of each energy commodity, and thus to define the different terms and definitions. In order to achieve this objective, the Ad Hoc Group of Experts was split into three sub-groups, covering separately coal and minerals, petroleum, and uranium, and they attempted to harmonize each commodity classification with the three major internationally recognized energy resource classifications, namely: the UN/CMMI for coal; the SPE/WPC/AAPG for petroleum; and the IAEA/ NEA for uranium. Substantive work was done in cooperation with the abovementioned organizations. At its thirteenth session in November 2003, the UNFC was adopted worldwide. At its fifty-ninth session in February 2004, the UNFC was recommended worldwide (UNFC, 2004). 


\section{The United Nations Framework Classification (UNFC) System}

The UNFC system is flexible and capable of meeting the requirements for application at national, industrial and institutional level, as well as to be successfully used for international communication and global assessments. Furthermore, it is harmonized with the SPE/WPC/AAPG Petroleum Resource Classification, see Fig. 8. During its completion, intensive consultations were held with a number of professional and intergovernmental organizations dealing with reserves evaluation, management and accounting (UNFC, 2004).

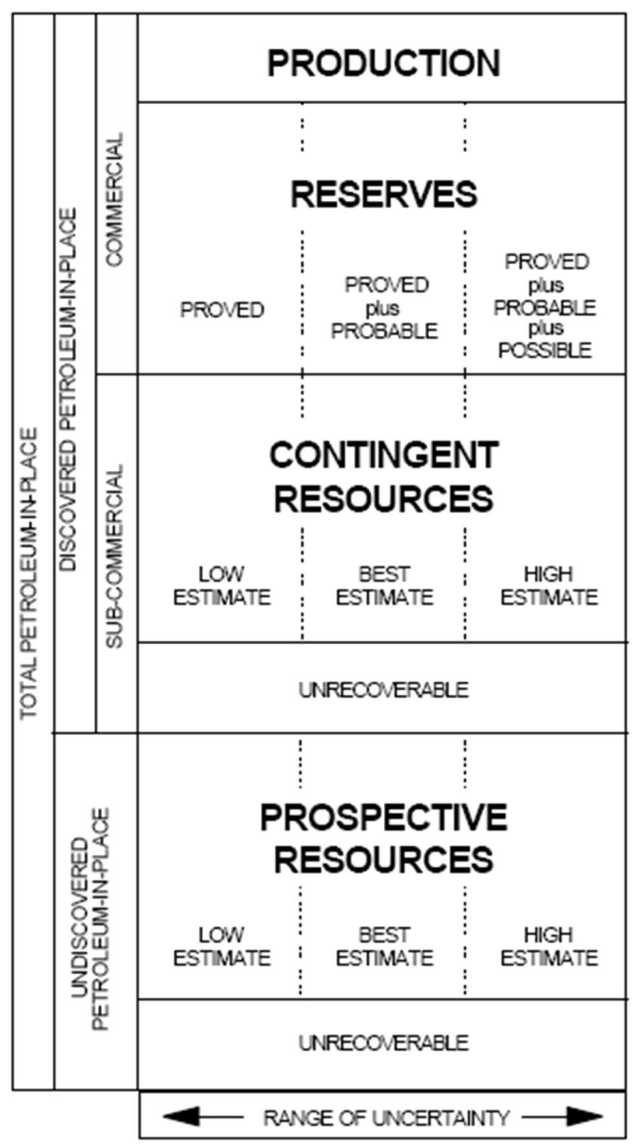

Fig. 8. The SPE/WPC/AAPG classification.

In this system, the total petroleum quantities initially in-place are described in terms of: 1) Produced quantities, 2) Remaining recoverable quantities, and 3) Additional quantities remaining in-place, (Fig. 9). The main focus of the UNFC is on the remaining recoverable quantities. 


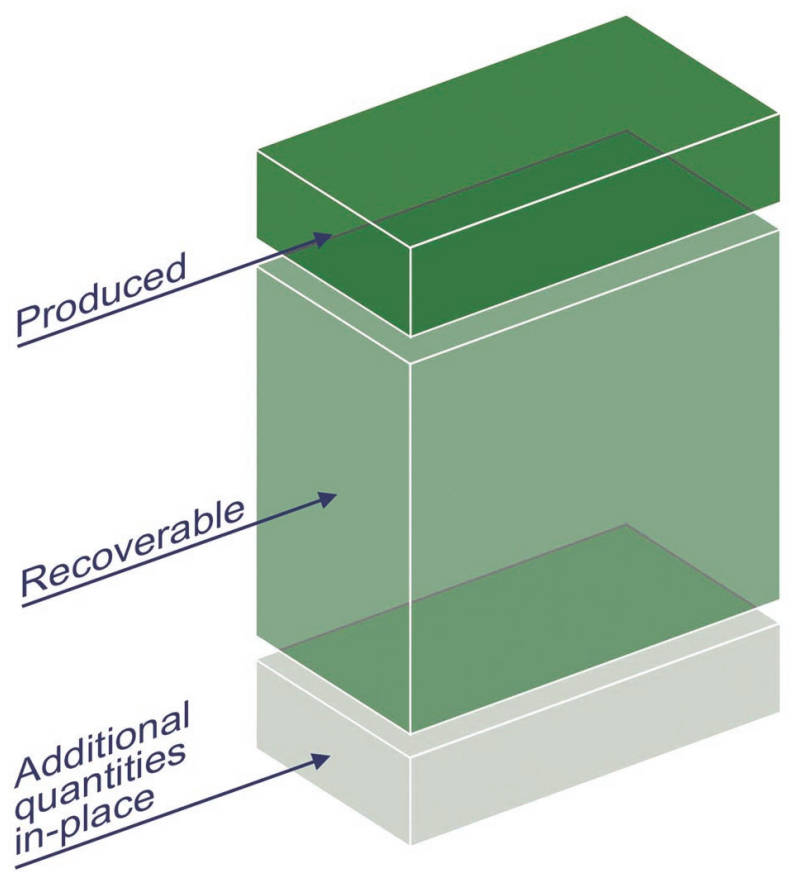

Fig. 9. Total initial-in-place petroleum.

\section{Produced Quantities}

Produced quantities are included in the UNFC to facilitate explanation of changes in remaining recoverable quantities resulting from production that has already occurred. Produced quantities are the sum of sales quantities and nonsales quantities as determined at their respective reference points between a specified initial time (often the time of first recorded production) up to a given date and time (normally the time of the evaluation). Non-sales quantities are considered to have intrinsic economic value.

\section{Remaining Recoverable Quantities}

Remaining recoverable quantities are the sum of sales quantities and nonsales quantities estimated to be produced at the respective reference points from a given date and time forward.

\section{Additional Quantities Remaining In-Place}

Additional quantities remaining in-place are quantities estimated to be in-place at the initial time, less the sum of the produced quantities and the estimated remaining recoverable quantities. Additional quantities remaining inplace are described in non-economic terms only. Their recoverability and, as a 
result, their economic viability, has not been assessed. Alternatively quantities may be non-economic in the sense that they may not be recovered in the future, although they may be an integral part of the recovery operations. Both forms of additional quantities remaining in place may hold intrinsic economic value, as do the recoverable non-sales quantities.

\section{Classification}

The remaining recoverable quantities are categorized using the three essential criteria affecting their recoverability: 1) Economic and commercial viability (E). 2) Field project status and feasibility (F). 3) Geological knowledge (G). Most of the existing resource classifications recognize these explicitly or implicitly. By making them explicit, the UNFC becomes a framework that allows for harmonization of existing classifications. The three criteria are easily visualized in three dimensions as shown in Fig. 10. Furthermore, three main categories are used to describe the $\mathrm{E}$ axis, three to describe the $\mathrm{F}$ axis, and four to describe the $\mathrm{G}$ axis as shown in Fig. 11-12.

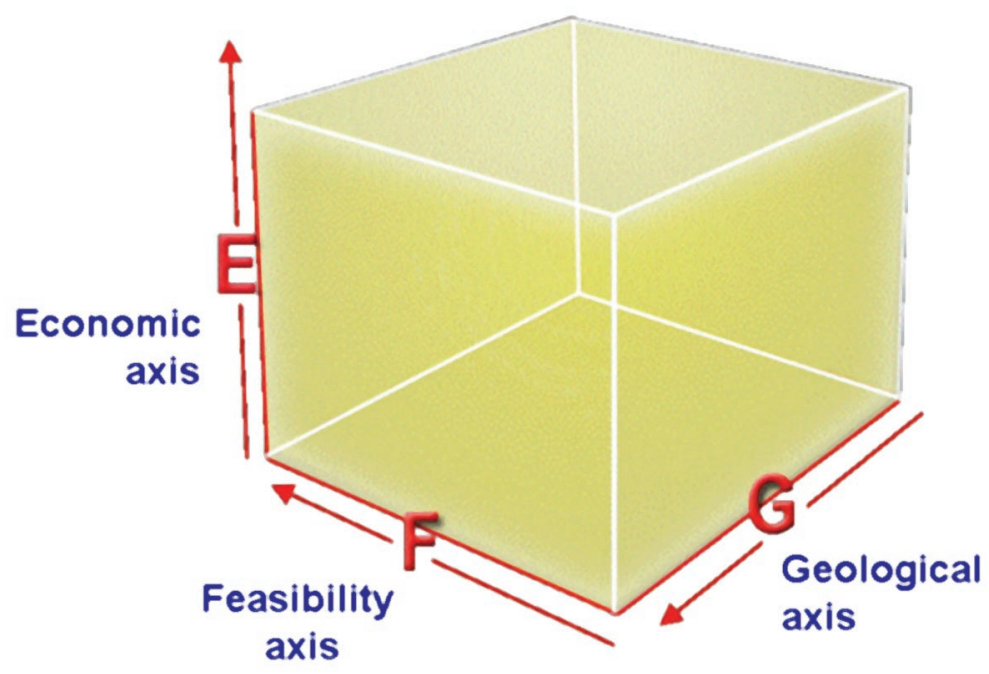

Fig. 10. Principal elements of the UNFC.

The three dimensions of categorization are represented by the edges of a cube. The digits are quoted in the order EFG firstly because the alphabetical order is easy to memorize, and secondly because the first digit refers to the economic viability, which is of decisive interest to producers, investors and host countries. Numbers are used to designate the different classes. Number 1, in accordance with the usual perception that the first is the best, refers to the highest degree of economic viability on the $\mathrm{E}$ axis, the most advanced project status on the $\mathrm{F}$ axis and the highest quality assessment on the $\mathrm{G}$ axis. 


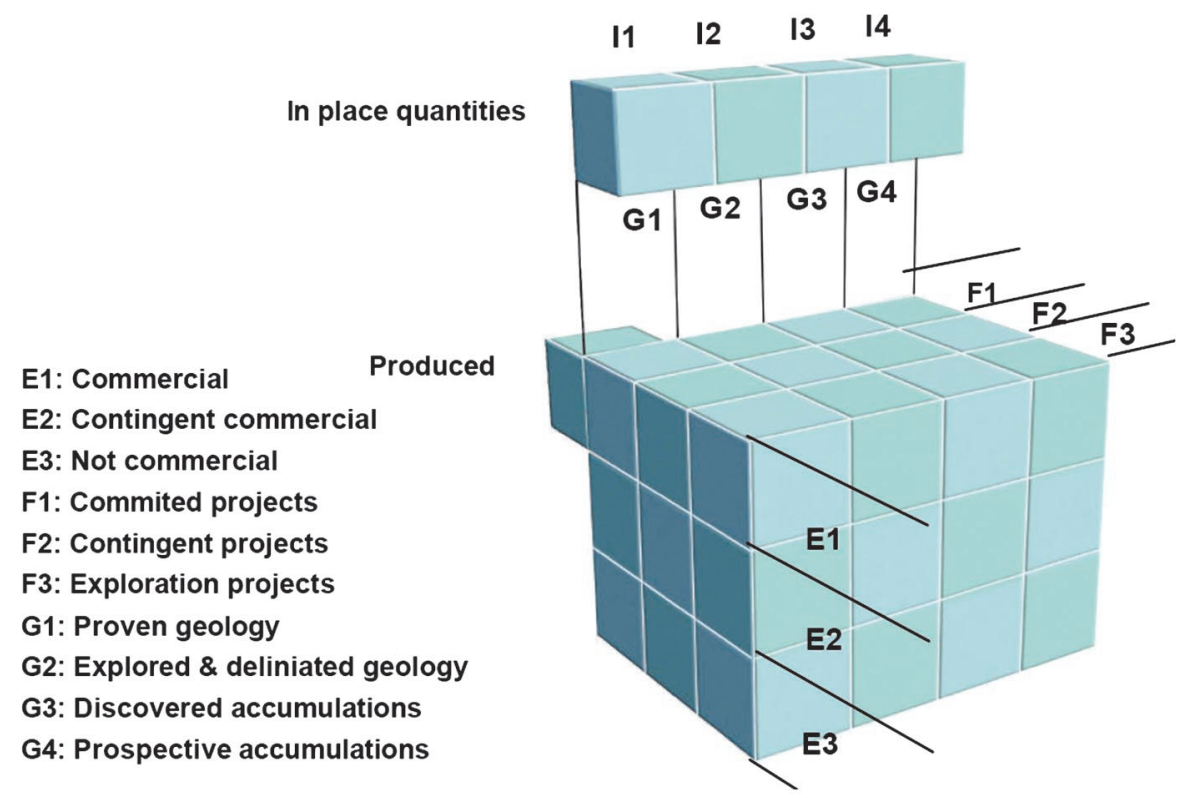

Fig. 11. The UNFC for petroleum (Blystad, 2003).

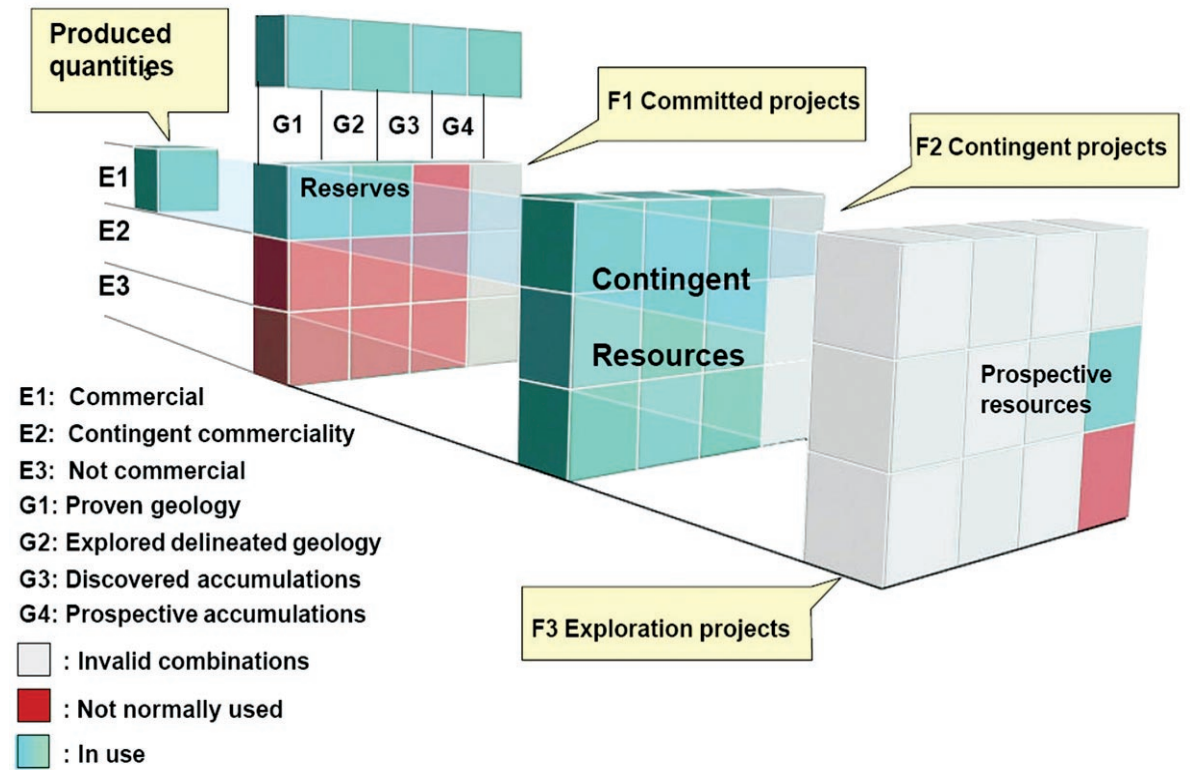

Fig. 12. The UNFC quantities for petroleum (Blystad, 2003). 
The use of categories is different for fluids and for solids. This is primarily due to the fact that fluids may flow in a reservoir, irrespective of the level of geological knowledge, see Fig. 12.

\section{Codification}

Due to variation between terminologies in different systems and languages, it is recommended to use only three-digit numeric codes for individual categories, so that they will be universally understood. For this to be possible, the sequence is always fixed, so that the quantity characterized as E1; F1; G1 may be written in number form as 111, independent of languages. In practice, only a limited number of combinations (classes) are valid. See Table 1 for a list of the categories and subcategories for petroleum.

Table 1. Categories and subcategories for petroleum.

\begin{tabular}{|l|l|}
\hline Category & \multicolumn{1}{|c|}{ Description } \\
\hline E1 & Economic \\
E1.1 & Normal Economic \\
E1.2 & Exceptional Economic \\
E2 & Potentially Economic \\
E2.1 & Marginal Economic \\
E2.2 & Sub-Marginal Economic \\
E3 & Intrinsically Economic \\
E3.1 & Non-sales \\
E3.2 & Undetermined \\
E3.3 & Unrecoverable \\
F1 & Justified Development and/or Production Project \\
F1.1 & Project in Production \\
F1.2 & Committed Development Project \\
F1.3 & Uncommitted Development Project \\
F2 & Contingent Development Project \\
F2.1 & Under Justification \\
F2.2 & Unclarified or On hold \\
F2.3 & Not Viable \\
F3 & Project Undefined \\
G1 & Reasonably Assured Geological Conditions \\
G2 & Estimated Geological Conditions \\
G3 & Inferred Geological Conditions \\
G4 & Potential Geological Conditions \\
\hline
\end{tabular}

\section{Harmonisation}

The incorporation of existing classification systems into the UNFC and their comparison is simplified by means of codification acting as an interface. Existing resource inventories that are classified using one or two of the sets of criteria 
may initially be retained projecting the resources onto the relevant axis or plane of the UNFC. As resources are being re-evaluated, the missing categories are easily identified, allowing the old inventory to be migrated into a full UNFC inventory.

\section{Quantification}

Quantities in classes may be represented by one or more discrete estimates or by a probability distribution that reflects the range of uncertainty in the estimate of that quantity. When a quantity is represented by a probability distribution, a low, best and high estimates shall be quoted: 1) The low estimate shall have a $90 \%$ probability of being exceeded and shall be designated $\mathrm{P}_{90}$. 2) The best estimate shall be any of the mean (expected) value, the most probable (mode) value or the median $\left(\mathrm{P}_{50}\right)$ value. It shall be stated which statistical measure has been used for the estimate. 3) The high estimate shall have a $10 \%$ probability of being exceeded and shall be designated $\mathrm{P}_{10}$. When a quantity is represented by several discrete estimates there shall be quoted, as a minimum, a low, a best and a high estimate, where such estimates shall reflect the same principles, and approximately the same probabilities, as would be associated with estimates derived from a probability distribution and quoted above. When a quantity is represented by a single discrete estimate, this shall be the best estimate unless otherwise stated.

\section{Classes of Remaining Petroleum Quantities}

Classes of remaining recoverable quantities of petroleum may be defined by using combinations of $\mathrm{E}, \mathrm{F}$ and $\mathrm{G}$ categories as follows:

1. Reserves : code 111,112,113

2. Contingent Resources : code 121, 122, 123, 221, 222, 223, 321, 322, 323, 331, 332, 333.

3. Prospective Resources : code 334. Committed Reserves are subset of reserves restricted to F1.1 and F1.2.

\section{Unrecoverable Quantities}

These are estimated to remain in-place after the completion of all relevant development and production projects. It is therefore not practical to categorize them by field project status and technical feasibility. Classes of unrecoverable quantities are defined with respect to geological assessment $\mathrm{G}$. Their economic viability is categorized as E3.2. They may be visualised to be contained in the front row of the unnumbered colourless boxes in Fig. 11. 
As an example, a class of unrecoverable quantities in an accumulation where the geology is reasonably assured will be defined by categories E3.2, all of F1 and F2 and F3, G1, or in numerical codes: $3.2 ; 1 ; 1$ and $3.2 ; 2 ; 1$ and $3.2 ; 3 ; 1$.

\section{Proved, Probable and Possible Petroleum Reserves}

Proved petroleum reserves are specifically defined below. The terms probable and possible petroleum reserves are broad terms that are widely used in the petroleum industry. The meaning assigned to them varies. The SPE/WPC definitions relate proved + probable $(2 \mathrm{P})$ reserves directly to the best estimate of committed reserves as defined above. Likewise, proved + probable + possible (3P) reserves relate directly to the high estimate of committed reserves. In order to make full use of the precision offered by the UNFC, it is recommended not to use the broader, and somewhat ambiguous, terms probable and possible reserves. Instead, the terms low, best and high estimates may be used stating precisely the classes of interest.

In the context of geological knowledge, which includes considerations of reservoir production characteristics, it is intended that category G1 would generally correspond to the level of technical confidence required for proved reserves. Similarly, categories G2 and G3 correspond to the levels of confidence associated with probable and possible reserves respectively. A particular assessment must however also include appropriate consideration of the level of confidence resulting from uncertainties with respect to economic and commercial viability and with respect to field project status and feasibility.

\section{Proved Petroleum Reserves}

Proved reserves are a specifically defined subset of committed reserves. Proved reserves are those quantities of petroleum which, by analysis of geological and engineering data, can be estimated with reasonable certainty to be commercially recoverable, from a given date forward, from known accumulations and under current economic conditions, operating methods, and government regulations. Proved reserves can be categorized as developed or undeveloped.

If deterministic methods are used, the term reasonable certainty is intended to express a high degree of confidence that the quantities will be recovered. If probabilistic methods are used, there should be at least a $90 \%$ probability that the quantities actually recovered will equal or exceed the estimate.

Proved developed reserves are a particularly important subset of proved reserves. They allow the recognition of reserves for which the investments have been made and are accounted for. They are defined as follows: Proved devel- 
oped reserves are quantities of proved reserves that are estimated to be recovered from existing wells and which will be processed and transported to market using facilities and infrastructure that exist at the date of the estimate.

\section{Reserves Estimations}

The process of estimating oil and gas reserves for a producing field continues throughout the life of the field. There is always uncertainty in making such estimates. The level of uncertainty is affected by the following factors:

1. Reservoir type,

2. Source of reservoir energy,

3. Quantity and quality of the geological, engineering, and geophysical data,

4. Assumptions adopted when making the estimate,

5. Available technology, and

6. Experience and knowledge of the evaluator.

The magnitude of uncertainty, however, decreases with time until the economic limit is reached and the ultimate recovery is realized, see Fig. 13.

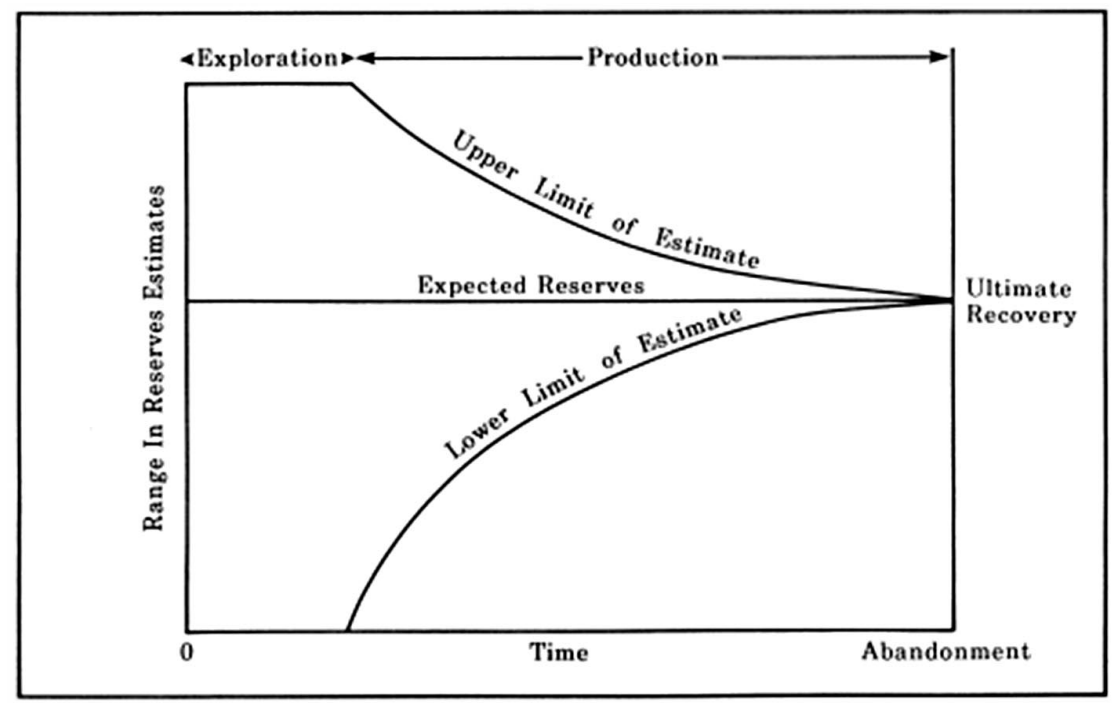

Fig. 13. Magnitude of uncertainty in reserve estimates (Robinson, 2000).

In the early stages of development, reserves estimates are restricted to the analogy and volumetric calculations. The analogy method is applied by comparing factors for the analogous and current fields or wells. A close-toabandonment analogous field is taken as an approximate to the current field. This method is most useful when running the economics on the current field; which is supposed to be an exploratory field. 
The volumetric method, on the other hand, entails determining the areal extent of the reservoir, the rock pore volume, and the fluid content within the pore volume. This provides an estimate of the amount of hydrocarbons-in-place. The ultimate recovery, then, can be estimated by using an appropriate recovery factor. Each of the factors used in the calculation above have inherent uncertainties that, when combined, cause significant uncertainties in the reserves estimate.

As production and pressure data from a field become available, decline analysis and material balance calculations, become the predominant methods of calculating reserves. These methods greatly reduce the uncertainty in reserves estimates; however, during early depletion, caution should be exercised in using them. Decline curve relationships are empirical, and rely on uniform, lengthy production periods. It is more suited to oil wells, which are usually produced against fixed bottom-hole pressures. In gas wells, however, wellhead back-pressures usually fluctuate, causing varying production trends and therefore, not as reliable.

The most common decline curve relationship is the constant percentage decline (exponential). With more and more low productivity wells coming on stream, there is currently a swing toward decline rates proportional to production rates (hyperbolic and harmonic). Although some wells exhibit these trends, hyperbolic or harmonic decline extrapolations should only be used for these specific cases. Over-exuberance in the use of hyperbolic or harmonic relationships can result in excessive reserves estimates.

Material balance calculation is an excellent tool for estimating gas reserves. If a reservoir comprises a closed system and contains single-phase gas, the pressure in the reservoir will decline proportionately to the amount of gas produced. Unfortunately, sometimes bottom water drive in gas reservoirs contributes to the depletion mechanism, altering the performance of the non-ideal gas law in the reservoir. Under these conditions, optimistic reserves estimates can result.

When calculating reserves using any of the above methods, two calculation procedures may be used: deterministic and/or probabilistic. The deterministic method is by far the most common. The procedure is to select a single value for each parameter to input into an appropriate equation, to obtain a single answer. The probabilistic method, on the other hand, is more rigorous and less commonly used. This method utilizes a distribution curve for each parameter and, through the use of Monte Carlo Simulation; a distribution curve for the answer can be developed. Assuming good data, a lot of qualifying information can be derived from the resulting statistical calculations, such as the minimum and maximum values, the mean (average value), the median (middle value), the mode (most likely value), the standard deviation and the percentiles, see Fig. 14 and 15 . 


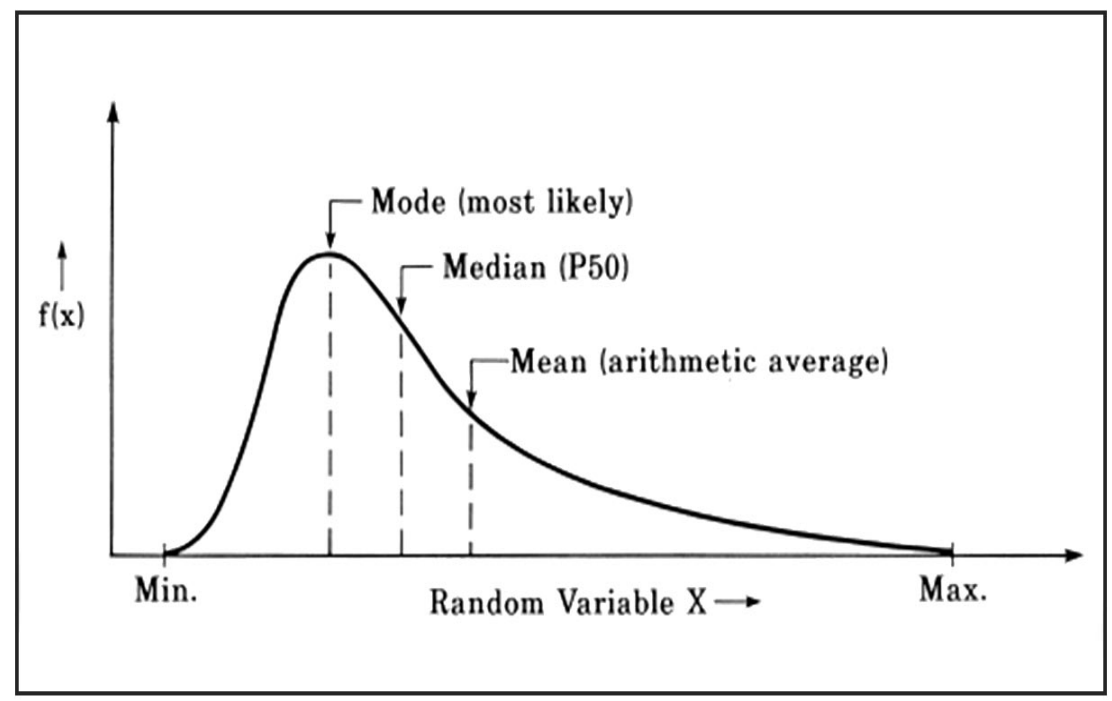

Fig. 14. Measures of central tendency (Robinson).

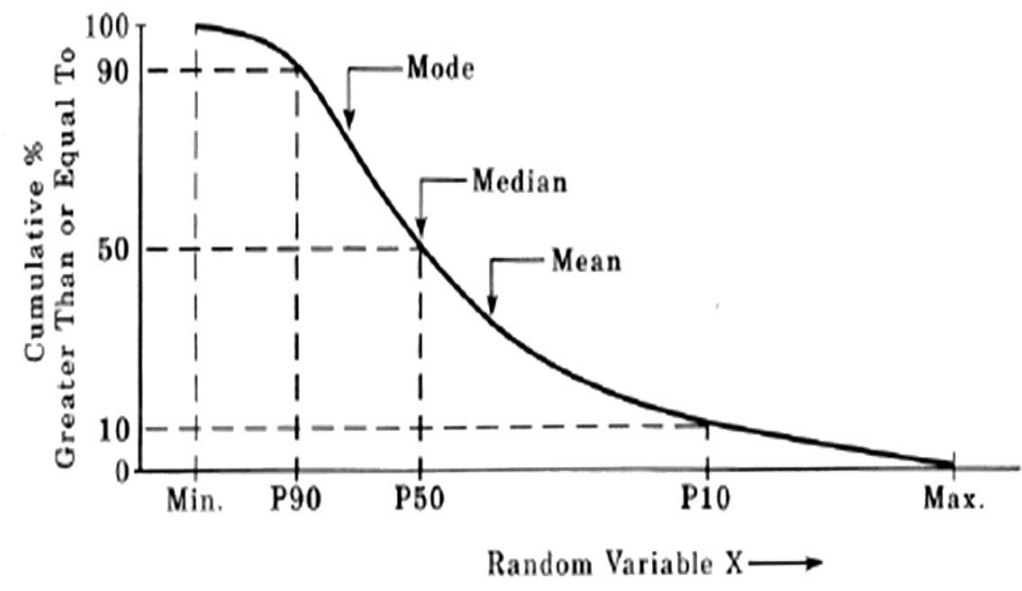

Fig. 15. Percentiles (Robinson, 2000).

The probabilistic methods have several inherent problems. They are affected by all input parameters, including the most likely and maximum values for the parameters. In such methods, one can not back calculate the input parameters associated with reserves. Only the end result is known but not the exact value of any input parameter. On the other hand, deterministic methods calculate reserve 
values that are more tangible and explainable. In these methods, all input parameters are exactly known; however, they may sometimes ignore the variability and uncertainty in the input data compared to the probabilistic methods which allow the incorporation of more variance in the data.

A comparison of the deterministic and probabilistic methods, however, can provide quality assurance for estimating hydrocarbon reserves; i.e. reserves are calculated both deterministically and probabilistically and the two values are compared. If the two values agree, then confidence on the calculated reserves is increased. If the two values are away different, the assumptions need to be reexamined.

\section{Conclusions}

1. With conventional sources becoming depleted, oil industry is directing itself towards higher risk ventures, such as shallow gas, heavy oil, and the more complex reservoirs.

2. There are as many reserves definitions in place today as there are stakeholders in the industry, each one fulfilling a specific purpose. Despite the efforts of SEC, SPE/WPC, and SPE/WPC/AAPG to standardize reserves, multiple reserve definitions remain in use. Many companies and agencies retain their own definitions which, while close to the SPE standard, have certain idiosyncrasies resulting from law and regulatory requirements, corporate policy decisions and/or ingrained habit. This is particularly true regarding the boundary between Proved and Unproved and, to a lesser extent, the sub-categories within Proved.

3. The wording of reserve definitions is sufficiently vague, allowing evaluators a great deal of latitude when classifying reserves. This freedom, coupled with companies' pressure to look good in the financial market, has resulted in a bending of the rules.

4. It looks that the word reserves cannot have a specific value, but can only represent a value in an abstract sense; i.e. it can never be a fixed volume but it can and does change from time to time and from observer to observer.

5. There is always uncertainty in making reserves estimates. The level of which is affected by the reservoir type, source of reservoir energy, quantity and quality of the geological, engineering, and geophysical data, assumptions adopted when making the estimate, underlying economics and politics, available technology, and experience and knowledge of the evaluator.

6. In order to avoid a situation where reserves lose all meaning as a comparative measure, it is necessary that the industry adopt a definition for reserves in order to provide some broadly accepted constraints on the conditions that would result in the estimation of reserves. Without a definition as a guideline or refer- 
ence, a volume labeled as reserves could be anything but would have no meanproduction figures are reported.

7. The sources, from which world oil reserves and production figures are reported, have inconsistency in the figures they report; and their numbers are taken to represent accurate figures which causes confusion to those who quote them.

8. Reserve growth has contributed substantial additional reserves over the last two decades. It is the most important problem in assessing the future production.

9. Recovery factor does not depend solely on technology; instead it depends on geology and quality of the reservoir, quality and type of recovery, quality of the production scheme, and present technology.

10. The SPE/WPC/AAPG and the UNFC classification systems need to be harmonized to enhance communication, make terms comparable and compatible, provide a methodology for evaluating resources on a common basis, and improved support for financial reporting.

11. OPEC and non-OPEC members need to conform to and test the efficiency and completeness of the UNFC classification systems.

12. Politics and prevailing economic conditions play an important role in reporting reserves. Therefore tighter controls need to be put on the sources, from which reserves and production figures are reported.

\section{Acknowledgments}

I would like to thank OPEC management, headed by Dr. Adnan ShihabEldin, for their support. I also thank the management of King Abdulaziz University for giving me the chance to join OPEC Secretariat during their Summer Fellowship Program, July-August 2004.

\section{References}

Ahlbrandt, T.S., Blystad, P., Young, E.D., Slavov, S. and Heiberg, S. (2003) The United Nations Framework Classification for World Petroleum Resources, SPE Paper 84142.

Al-Tayyeb, M. and Dahmani, A. (2003) The Outcome of the Seminar on the Application of the UN Framework Classification on Energy Reserves/Resources to OPEC Member Countries, OPEC Bulletin, pp: 17-23.

Blystad, P. (2003) Application of UN Framework Classification to Petroleum, A Presentation to the OPEC Secretariat.

Haider, G.M. (2000) World Oil Reserves: Problems in Definition and Estimation, OPEC Review. 
Laherrere, J.H. (1998) The Evolution of the World's Hydrocarbon Reserves, Retrieved: 7, 15, 2004, from http://dieoff.org/page178.pdf\#search=\%22\%22Laherrere\%22\%20\%22The\% 20 Evolution\%22\%22.

Occidental Petroleum Corporation (2002) A Comparison of Several Definitions of Oil and Gas Reserves, A .PDF file that can be obtained from the author.

OPEC (2002 and 2003) Annual Statistical Bulletin.

Psenner, M. (2004) Personal Contact, Data Services Department, OPEC Secretariat, Vienna, Austria.

Robinson, J.G. (2000) Reserves Estimation and Definitions: Standardizations and Enforcement, Retrieved, 7, 15, 2004 from http://www.cseg.ca/conferences/2000/2000abstracts/1145. PDF \#search $=\% 22$ Reserve

Salameh, M. (2004) How Realistic are OPEC's Proven Oil Reserves, PETROLEUM REVIEW.

United Nations Framework Classification (UNFC) for Energy and Mineral Resources (2004) Document UN Economic Commission for Europe, 59 ${ }^{\text {th }}$ Session, Document E/2004/ 37- E/ECE/1416. 


\title{
احتيــــاطي البترول وثغـــــــة المصداقيــــة
}

\author{
حسن سليمان ناجي

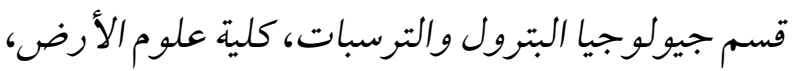

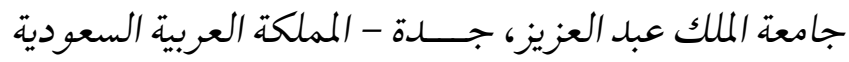

Email: hassan@petrobjects.com

المستخلص. يتناول هذا البحث دراسة التعاريف المتعددة لاحتياطي

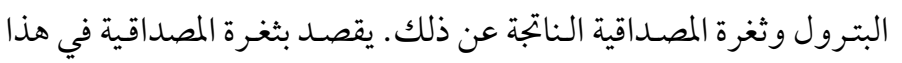

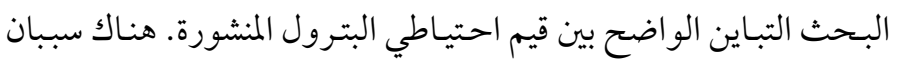

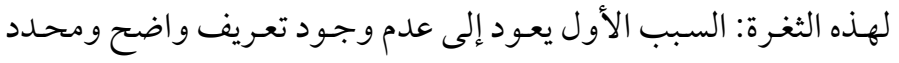

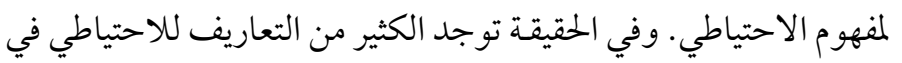

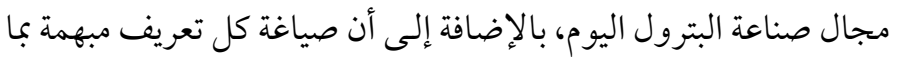

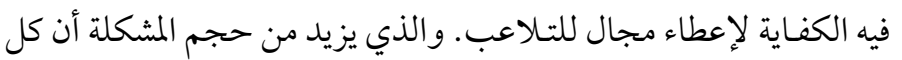

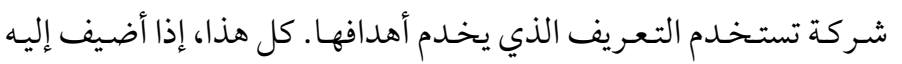

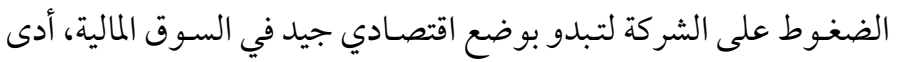

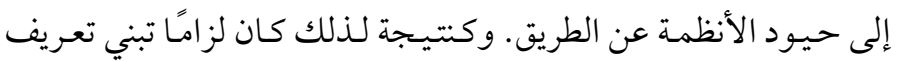

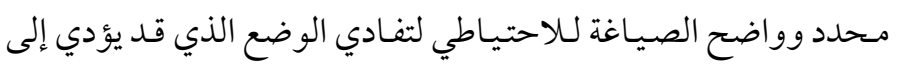
فقد مفهوم الاحتياطي لكل المعاني.

السبب الثاني لهذه الثغرة يعود إلى أن الاحتياطي كمية تقديرية،

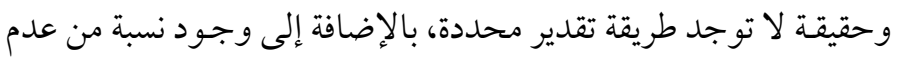

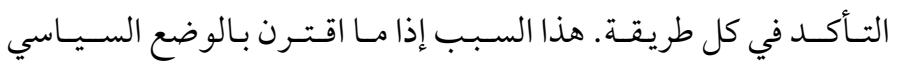

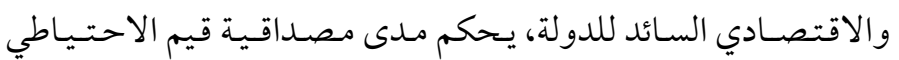

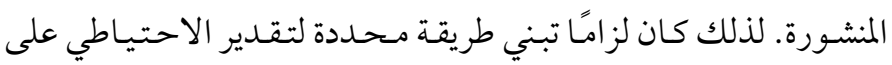
أساس موحد لتحسين الوضع وكسب الثقة. 